\title{
Developments of electrolyte systems for lithium-sulfur batteries: a review
}

\author{
Gaoran $\mathrm{Li}^{1}$, Zhoupeng $\mathrm{Li}^{1}$, Bin Zhang ${ }^{2}$ and Zhan Lin ${ }^{1 *}$ \\ ${ }^{1}$ College of Chemical and Biological Engineering, Zhejiang University, Hangzhou, Zhejiang, China \\ ${ }^{2}$ Anhui Academy for Environmental Science Research, Hefei, Anhui, China
}

\section{Edited by:}

Mariusz Walkowiak, Institute of Non-Ferrous Metals, Poland

Reviewed by:

Angu N. Lakshmi, Mahatma Gandhi University, India

Oscar Tutusaus, Toyota Research Institute of North America, USA Andrea Strakova Fedorkova, Pavol Jozef Safarik University in Kosice, Slovakia

*Correspondence:

Zhan Lin, College of Chemical and Biological Engineering, Zhejiang

University, Hangzhou, Zhejiang, China

e-mail: zhanlin@zju.edu.cn
With a theoretical specific energy five times higher than that of lithium-ion batteries $(2,600$ vs. $\sim 500 \mathrm{Wh} \mathrm{kg}^{-1}$ ), lithium-sulfur (Li-S) batteries have been considered as one of the most promising energy storage systems for the electrification of vehicles. However, both the polysulfide shuttle effects of the sulfur cathode and dendrite formation of the lithium anode are still key limitations to practical use of traditional Li-S batteries. In this review, we focus on the recent developments in electrolyte systems. First, we start with a brief discussion on fundamentals of Li-S batteries and key challenges associated with traditional liquid cells. We then introduce the most recent progresses in liquid systems, including ether-based, carbonate-based, and ionic liquid-based electrolytes. And then we move on to the advances in solid systems, including polymer and non-polymer electrolytes. Finally, the opportunities and perspectives for future research in both the liquid and solid Li-S batteries are presented.

Keywords: Li-S batteries, energy storage, polysulfide, electrolytes, review

\section{INTRODUCTION}

With the development of modern society and the boost of the electronics industry, energy storage systems have attracted considerable attention during the past few decades. Among them, lithium-ion (Li-ion) batteries have been intensely studied on their stable electrochemistry and long lifespan for applications in portable electronic devices. However, Li-ion batteries are still suffering approaching limiting capacity and high cost with safety concerns. This makes them inferior to support emerging industrial applications, including military power supplies, electric vehicles, and stationary electrical grids, which need higher capacity, lower cost, and more secured operation (Tarascon and Armand, 2001; Li et al., 2009; Ellis et al., 2010; Goodenough and Kim, 2010; Etacheri et al., 2011).

Recently, lithium-sulfur ( $\mathrm{Li}-\mathrm{S}$ ) batteries attract considerable attentions due to high theoretically gravimetric and volumetric energy densities of $2,600 \mathrm{Wh} \mathrm{kg}^{-1}$ and $2,800 \mathrm{Wh} \mathrm{L}^{-1}$, respectively. Based on the complete reaction between the metallic lithium and elemental sulfur to form lithium sulfide $\left(\mathrm{Li}_{2} \mathrm{~S}\right)$ as shown in Eq. 1:

$$
\mathrm{S}+2 \mathrm{Li} \rightarrow \mathrm{Li}_{2} \mathrm{~S}\left(E^{\mathrm{o}}=2.20 \mathrm{~V} \text { vs. } \mathrm{Li} / \mathrm{Li}^{+}\right)
$$

Lithium-sulfur batteries can supply the energy density three to fivefolds higher than Li-ion batteries. Combined with other advantages of sulfur such as the natural abundance, cheapness, and non-toxic, Li-S batteries have been considered as one of the most promising energy storage devices for next generation high-energy power systems.

A typical Li-S cell is shown in Figure 1, which include carbonsulfur composites as the cathode and metallic lithium as the anode with organic liquid electrolyte in between. During discharge, sulfur is electrochemically reduced into $\mathrm{Li}_{2} \mathrm{~S}$ on the electrode through a complex process with a series of polysulfide intermediates.

A typical discharge profile of sulfur cathode in the liquid electrolyte is shown in Figure 2. The active sulfur is electrochemically reduced through a stepwise sequence of a series of intermediates in formula as $\operatorname{Li}_{2} S_{\mathrm{x}}(\mathrm{x}=2 \sim 8)$ on the electrode surface, among which the long-chain polysulfide $\mathrm{Li}_{2} \mathrm{~S}_{\mathrm{x}}(\mathrm{x}=4 \sim 8)$ is demonstrated highly soluble in the electrolyte while the short-chain $\mathrm{Li}_{2} \mathrm{~S}_{\mathrm{x}}(\mathrm{x}=2 \sim 4)$ is less soluble (Ji and Nazar, 2010; Yang et al., 2013).

The lithiation of sulfur can briefly described as four processes below:

$$
\begin{gathered}
\mathrm{S}_{8}+2 \mathrm{e}^{-} \rightarrow \mathrm{S}_{8}^{2-} \\
\mathrm{S}_{8}^{2-}+2 \mathrm{e}^{-} \rightarrow 2 \mathrm{~S}_{4}^{2-} \\
(2 x+2 y) \mathrm{Li}^{+}+\left(\frac{2 x+y}{4}\right) \mathrm{S}_{4}^{2-} \\
+\frac{2 x+3 y}{2} \mathrm{e}^{-} \rightarrow x \mathrm{Li}_{2} \mathrm{~S}_{2}+y \mathrm{Li}_{2} \mathrm{~S} \\
2 \mathrm{Li}^{+}+\mathrm{Li}_{2} \mathrm{~S}_{2}+2 \mathrm{e}^{-} \rightarrow 2 \mathrm{Li}_{2} \mathrm{~S}
\end{gathered}
$$

The solid-state crown-like $S_{8}$ ring is first electrochemically reduced into highly soluble $S_{8}^{2-}$ through a solid-liquid two states reaction, exhibiting upper voltage plateau at $\sim 2.3 \mathrm{~V}$. Subsequently, the dissolved $\mathrm{S}_{8}^{2-}$ is further reduced into lower-order $\mathrm{S}_{4}^{2-}$ on the surface of cathode, accompanied with a series of chemical or electrochemical intermediates such as $\mathrm{S}_{6}^{2-}, \mathrm{S}_{3}^{2-}, \mathrm{S}_{3}^{-}$, etc. (Barchasz et al., 2012b; Zhang and Read, 2012). This process causes rapid increase of electrolyte viscosity due to increase of the polysulfides (PS) anions concentration, and results in a steeply decline of voltage until a downward peak is observed when the solution reaches maximum viscosity as shown in region 2 . The third process, which 


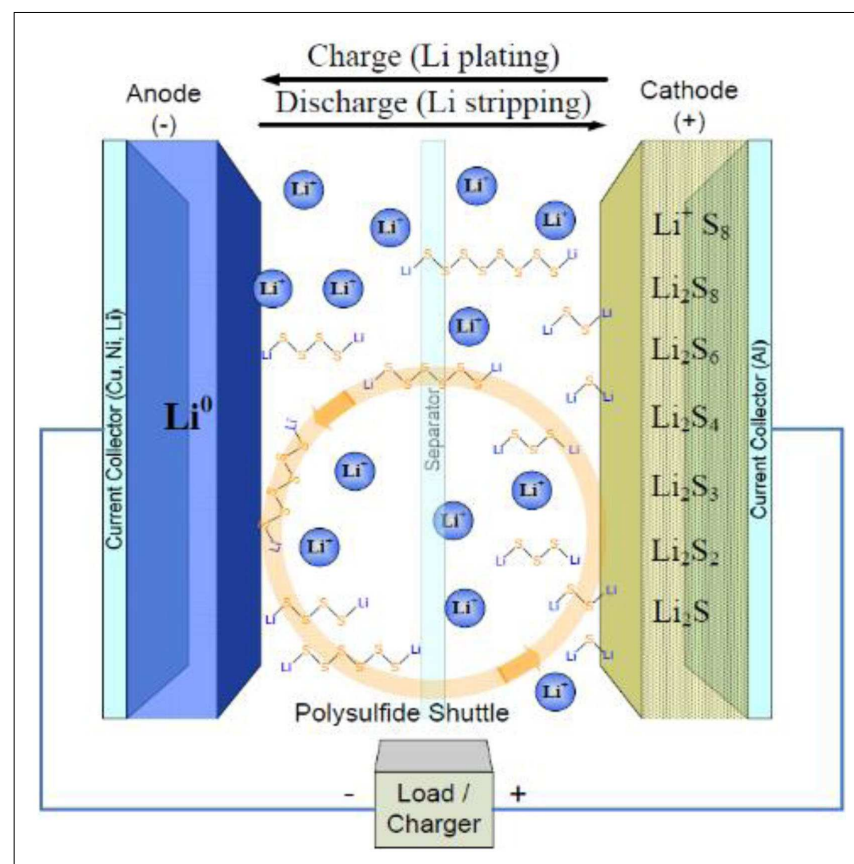

FIGURE 1 | Schematic configuration of Li-S battery based on organic liquid electrolyte (Mikhaylik et al., 2010).

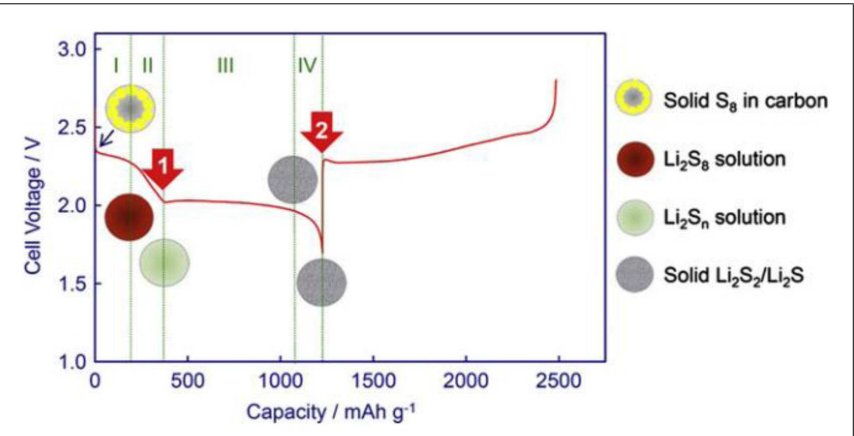

FIGURE 2 |A typical discharge profile of sulfur cathode in the liquid electrolyte (Ji and Nazar, 2010; Yang et al., 2013).

contributes the major capacity of Li-S cells, shows a long plateau at a lower potential of $\sim 2.1 \mathrm{~V}$, corresponding to the liquid-solid two phases reduction from dissolved low-order soluble PS to insoluble $\mathrm{Li}_{2} \mathrm{~S}_{2}$ or $\mathrm{Li}_{2} \mathrm{~S}$ as described in Eq. 4. The subsequent reduction from $\mathrm{Li}_{2} \mathrm{~S}_{2}$ to $\mathrm{Li}_{2} \mathrm{~S}$ is through a solid-solid single phase reaction. This process suffers poor kinetic and high polarization due to the sluggishness of ion diffusion in solid-state bulk and the electronic insulation natures of $\mathrm{Li}_{2} \mathrm{~S}_{2}$ and $\mathrm{Li}_{2} \mathrm{~S}$ (Yamin and Peled, 1983; Yamaki et al., 1998).

Despite the considerable advantages mentioned-above, Li-S batteries still suffer tough challenges for their practical applications: (1) the electronic and ionic insulation nature of sulfur and its discharge products deteriorate the utilization of active sulfur material. (2) The dissolution of polysulfide - intermediates of cathode reaction in conventional organic liquid electrolyte - results in the so-called "shuttle" effect and leads to a severe active material loss in the cathode and lithium corrosion in the anode. (3) The remarkable $76 \%$ volume change from $\mathrm{S}$ to $\mathrm{Li}_{2} \mathrm{~S}$ leads to the instability of cathode structure. (4) The adoption of metallic lithium anode results in the potential security liability due to the lithium dendrite formation and flammability in the organic liquid electrolyte.

A significant amount of effort and expertise have been invested to overcome the challenges mentioned-above, among which the novel design of sulfur cathode has received the maximum concentration in the purpose of elevating the electronic conductivity and suppressing the dissolution of PS (Ji and Nazar, 2010; Barghamadi et al., 2013; Bresser et al., 2013; Evers and Nazar, 2013; Manthiram et al., 2013, 2014; Song et al., 2013; Yin et al., 2013; Chen and Shaw, 2014; Xu et al., 2014). These works usually focused on constructing a conductive porous matrix, such as nanostructured carbons and conducting polymers, as holder for active sulfur species as well as to physically or chemically restrain the dissolution and diffusion of PS to alleviate active material loss and suppress the shuttle effect.

Except for the thriving cathode development in $\mathrm{Li}-\mathrm{S}$ batteries, the research on Li-S electrolytes, has also been accelerated recently due to its especial and critical role. The primary function of electrolyte for $\mathrm{Li}-\mathrm{S}$ batteries is to efficiently transport $\mathrm{Li}^{+}$ions between the electrodes. It generally requires adequately high $\mathrm{Li}^{+}$conductivity in the premise of physical, chemical, and electrochemical stabilities under operating conditions such as temperature, pressure, as well as the working voltage window. Moreover, the electrolyte has additionally critical influence on electrode reaction mechanisms and the behavior of active sulfur and its discharge products. In this review, we herein mainly aim to introduce some critical and instructive researches on different types of electrolytes presently applied in Li-S batteries, including liquid electrolytes such as ether-based, carbonate-based and ionic liquid (IL)-based electrolytes, and solid electrolytes such as polymer and non-polymer electrolytes. We also suggest some ways to rationally design novel electrolytes for future applications in $\mathrm{Li}-\mathrm{S}$ batteries, to enhance its electrochemical performance for longevity of Li-S cells.

\section{LIOUID ELECTROLYTES}

Liquid electrolyte is the most commonly used in not only Li-S batteries, but also most of other electrochemical cells, due to its low surface tensions and low viscosities. These properties provide electrolyte with good wettability to obtain favorable contact between electrolyte and active materials along with low interface resistance (Scheers et al., 2014). Meanwhile they also provide easier access to achieve large-scale applicable electrolytes with considerable ion conductivity, due to the easier ion diffusion as well as preparation of homogeneous solution. As for Li-S cells, special requirements need to be proposed for electrolyte, due to high chemical reactivity of PS and metallic lithium (Gao et al., 2011; Zhang, 2013). Moreover, taking the poor electrochemical kinetics of sulfur and lithium sulfide into consideration, more beneficial design of electronic and ionic paths should raise the difficulty in the electrolyte selection of Li-S cells (Scheers et al., 2014).

\section{ETHER BASED ELECTROLYTES}

At present, ether-based electrolyte is adopted as the most commonly used electrolyte for Li-S batteries, which is typically 
composed of $1 \mathrm{M}$ lithium bis-trifluoromethanesulfonimide (LiTFSI) in a binary ether solvent of 1,2-dimethoxyethane (DME) and 1,3-dioxolane (DOL) with a small amount of $\mathrm{LiNO}_{3}$ as additives (Gao et al., 2011; Kim and Jeong, 2011; Zhang, 2013; Xu et al., 2014). Ether solvents are chosen mainly because their general stability in the presence of PS (Aurbach et al., 1990a,b; Gofer et al., 1992) and high ion transmission and better electrolyte/electrode contact from the low-viscosity and excellent wettability (Zhang, 2013). In this section, we will discuss the ether-based electrolytes from the following three aspects: the solvents, the salts, and the additives.

\section{Solvents}

Among many types of ether solvents, chain-ether such as DME, polyethylene glycol dimethyl ethers (PEGDME), and tetraethylene glycol dimethyl ether (TEGDME) dominated the use as a single solvent for Li-S battery due to its good dissolving capacity against PS (Tobishima et al., 1997; Marmorstein et al., 2000; Shim et al., 2002; Barchasz et al., 2013a). Table 1 shows the list of solvents used in the present Li-S cells and their characteristics. For example, Mikhaylik group of Sion Power Corporation studied single DME, single DOL, and a binary solvent of $\mathrm{DME}+\mathrm{DOL}$ as the electrolyte for Li-S battery (Mikhaylik et al., 2010). DOL has relatively lower polysulfide solubility, but provides a more stable solid electrolyte interface (SEI) on the metallic lithium surface. DME, on the other hand, is more reactive with lithium, but provides higher polysulfide solubility for improved cathode reaction kinetics. These two electrolyte solvents exhibit some synergistic effect on improving the specific capacity and cycle life of lithium cells. Wang et al. (2010) used different electrolyte composition of DME: DOL $=4: 1,2: 1,1: 1,1: 2$, and 1:4 as solvents and $\mathrm{LiClO}_{4}$ as lithium salt. When using the optimal composition of DME:DOL $=2: 1(\mathrm{v} / \mathrm{v})$, the cell exhibited the highest initial capacity of $1,200 \mathrm{mAh}^{-1}$ and best cycling capacity retention of $750 \mathrm{mAh} \mathrm{g}^{-1}$ after 20 cycles. A followed EIS analysis indicated that high content of DME in electrolyte raised the interfacial resistance due to the formation of an impermeable layer on the surface of the sulfur cathode, while the increase of DOL could ameliorate this phenomenon. Parallel works were also conducted by Jung's group (Kim et al., 2014) and Lim's group (Kim et al., 2004).
Tetraethylene glycol dimethyl ether, with a glyme structure and low dielectric constant $\left(\varepsilon_{\mathrm{r}}=7.9\right)$, is another commonly used solvent for Li-S batteries. Barchasz et al. (2013b) carried out the study on the binary solvent consist of TEGDME and DOL in different volume ratio, as well as single TEGDME or DOL as solvent for $\mathrm{Li}-\mathrm{S}$ cells. The best performance was obtained when TEGDME/DOL $=25 / 75(\mathrm{v} / \mathrm{v})$ solvent composition was used. The solvation ability of the electrolyte was considered as a key factor for high electrochemical performance. These cells exhibited better performance than those with TEGDME when combined with DOL in volume ratio of 1:1 as reported by Barchasz et al. (2013a).

\section{Lithium salts}

Lithium salts require high chemical and electrochemical stability, considerable solubility, and high degree of dissociation in specific solvent to ensure good ion conductivity. Figure 3 shows the typical lithium salts already used in or of potential use for $\mathrm{Li}-$ $S$ cells. Among them, the most commonly used lithium salts in Li-S system are LiTFSI and LiTf (Foropoulos and Desmarteau, 1984; Xu, 2004; Scheers et al., 2014) due to the high thermal stability, good compatibility with ether solvents, and high dissociation ability. It is worth noting that LiTFSI and particularly LiTf were suffering $\mathrm{Al}$ corrosion problem starting as $\sim 2.8 \mathrm{~V}$ (Krause et al., 1997) and were not suggested to be used for most Li-ion battery. However, the lower cell voltage and less stringent condition on anodic stability of Li-S batteries liberates LiTFSI and LiTf from this problem as well as renewed the interest of some of other salts of intermediate anodic stability such as lithium bis(fluorosulfonyl)imide ( $\mathrm{Li}\left[\mathrm{N}\left(\mathrm{SO}_{2} \mathrm{~F}\right]_{2}\right.$, LiFSI) (Guerfi et al., 2008) and lithium 4,5-dicyano-2-trifluoromethylimidazolide (LiTDI) (Dudley et al., 1991; Xu and Angell, 2002). Meanwhile lithium perchlorate $\left(\mathrm{LiClO}_{4}\right)$ is also one of the alternatives by Wang et al. (2010). $\mathrm{LiClO}_{4}$ has also been studied by some other groups (Kim and Jeong, 2011), whose performance is usually inferior compared to LiTFSI or LiTf, presumably due to the inability to form a stable SEI on the lithium anode (Tarascon and Guyomard, 1994). As for $\mathrm{LiPF}_{6}$, a commonly used salt in Li-ion batteries, is rarely adopted in ether system due to the generation of Lewis acids, which decomposes the solvent (Armand, 1994). However, it is notable that until now there are few studies focusing on the influence of lithium salt on the performance of Li-S cells.

Table 1 |The list of solvents used in the present Li-S cells and their characteristics (Choi et al., 2007; Kodama et al., 2011; Barchasz et al., 2013a,b).

\begin{tabular}{|c|c|c|c|c|c|c|}
\hline Solvents & & $\mathbf{M}_{\mathbf{w}}$ & $\mathrm{T}_{\mathrm{b}}\left({ }^{\circ} \mathrm{C}\right)$ & $\mathrm{T}_{\mathrm{m}}\left({ }^{\circ} \mathrm{C}\right)$ & $\mu(\mathbf{c P})$ & $\varepsilon$ \\
\hline DME & 1,2-Dimethoxyethane & 90.12 & 85 & -69 & 0.46 & 7.3 \\
\hline TEGDME & Tetraethylene glycol dimethyl ether & 222.28 & 275 & -30 & 4.05 & 7.9 \\
\hline EEE & 2-Ethoxyethyl ether & 162.63 & 188 & -44.3 & 1.4 & - \\
\hline PEGDME & Poly ethylene glycol dimethyl ether & $\sim 250$ & $>250$ & -23 & 7.0 & - \\
\hline THF & Tetrahydrofuran & 72.11 & 66 & -108.4 & 0.48 & 7.6 \\
\hline
\end{tabular}

$M_{w}$, molecular weight; $T_{b}$, normal boiling point; $T_{m}$, normal melting point; $\mu$, viscosity at $25^{\circ} \mathrm{C} ; \varepsilon$, dielectric constant. 


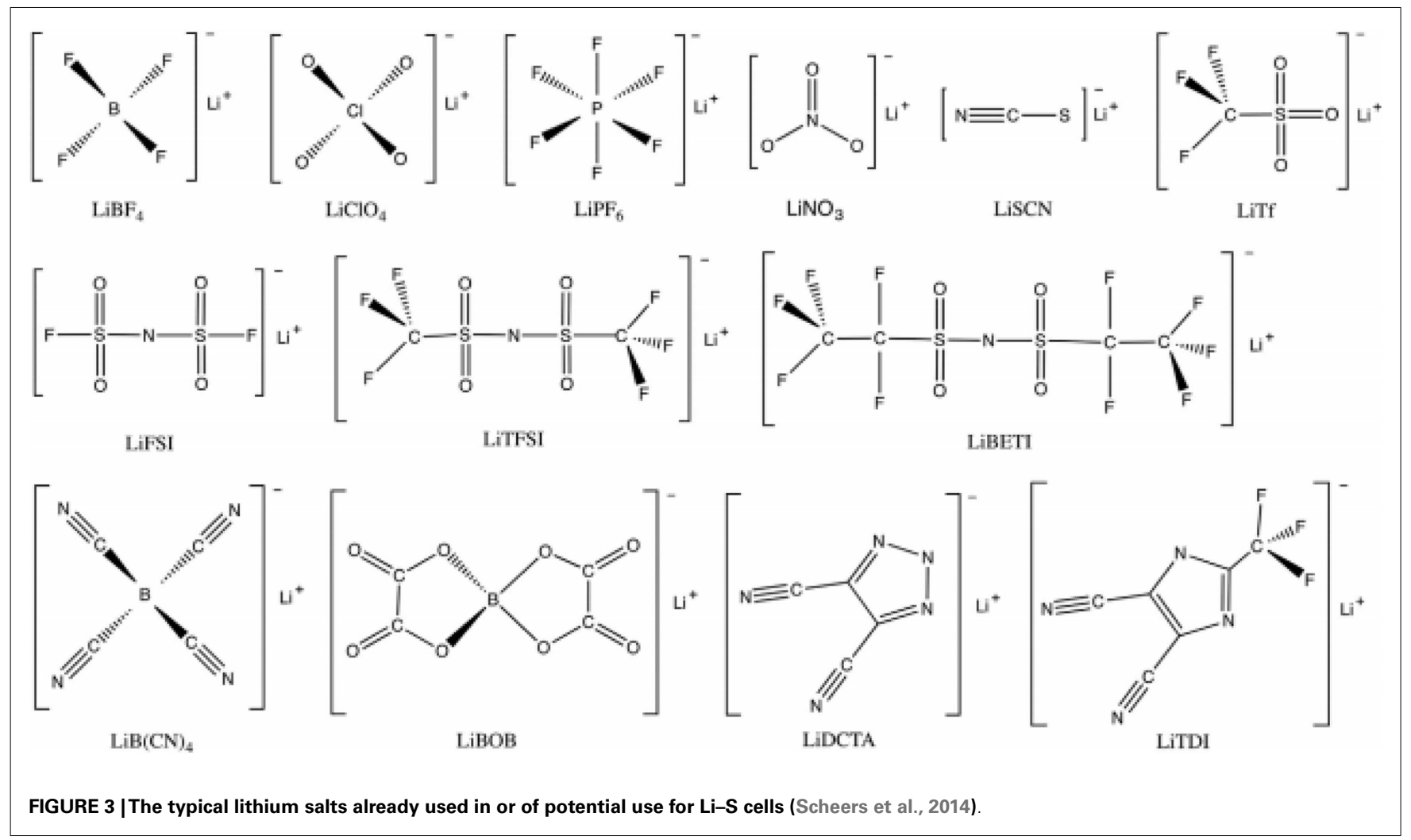

\section{Additives}

Most electrolytes for Li-S batteries contains small amount of additive in purpose of protecting lithium anode and enhancing the solubility and stability of PS. $\mathrm{LiNO}_{3}$ has become the most commonly used additive in Li-S battery since its first adoption in 2008. The functions of $\mathrm{LiNO}_{3}$ in $\mathrm{Li}-\mathrm{S}$ system were investigated in detail by Aurbach et al. (2009). The results showed that $\mathrm{LiNO}_{3}$ lead to a smaller impedance of $\mathrm{Li}$ foil while its reduction products $\mathrm{Li}_{\mathrm{x}} \mathrm{NO}_{\mathrm{y}}$ contribute to the formation of suitable surface film, protecting Li from further reaction with PS. However, the $\mathrm{LiNO}_{3}$ study by Zhang indicated that the beneficial anode passivation was accompanied by a less desired effect at the cathode (Zhang, 2012). During the first discharge, $\mathrm{LiNO}_{3}$ was found to be irreversible reduced at the carbon surface and the reduction products adversely affect the redox reversibility of active sulfur, with a negative impact on the capacity and cycle performance of the Li-S battery. It was recommended not to discharge the cell lower than $1.6 \mathrm{~V}$ to avoid the reduction problem of $\mathrm{LiNO}_{3}$ (Mikhaylik et al., 2010).

Polysulfides were also used as additives for Li-S electrolyte due to its participation in the formation of anode SEI (Demir-Cakan et al., 2013; Xiong et al., 2013). The liquid Li-S battery or catholyte concept represents the extreme of this strategy while the majority of the related works still focuses on the PS as additives in Li-S cells together with mesoporous S/C cathodes (Barchasz et al., 2012a; Zhang and Read, 2012; Zhang and Tran, 2012; Demir-Cakan et al., 2013). Xiong et al. (2013) investigated the formation of a stable solid two layered interface on the surface of metallic lithium by cycling symmetric $\mathrm{Li} / \mathrm{Li}$ and $\mathrm{Li} / \mathrm{S}$ cells with $0.2 \mathrm{M} \mathrm{Li}_{2} \mathrm{~S}_{6}$ as a co-salt in $0.8 \mathrm{M}$ LiTFSI DOL:DME $(1: 1 \mathrm{v} / \mathrm{v})$ electrolyte. The top layer was composed of the decomposition products of LiTFSI owing to the initial contact with lithium anode. The inner layer was consisted of the reduction product by the chemical reaction between lithium metal and PS in electrolyte. Xiong et al. suggested that the inner layer efficiently prevented continuous decomposition of LiTFSI, while the top layer cannot efficiently suppress the PS shuttle. Another novel additive, phosphorous pentasulfide $\left(\mathrm{P}_{2} \mathrm{~S}_{5}\right)$ was introduced by Liang's group (Lin et al., 2013a). The function of $\mathrm{P}_{2} \mathrm{~S}_{5}$ was introduced in two sides: (1) $\mathrm{P}_{2} \mathrm{~S}_{5}$ promotes the dissolution of $\mathrm{Li}_{2} \mathrm{~S}$ and alleviates the capacity loss caused by the precipitation of $\mathrm{Li}_{2} \mathrm{~S}$, and (2) $\mathrm{P}_{2} \mathrm{~S}_{5}$ takes part in the formation of passivation layer on the surface of lithium metal, and therefore eliminates the polysulfide shuttle phenomenon. A Li-S test cell demonstrated a high reversible capacity of $900-1,350 \mathrm{mAh} \mathrm{g}^{-1}$ and a high coulombic efficiency of $\geq 90 \%$ for 40 stable cycles at $\mathrm{C} / 10$.

\section{CARBONATE-BASED ELECTROLYTES}

Carbonate-based electrolyte, typically composed of $1 \mathrm{M} \mathrm{LiPF}_{6}$ dissolved in binary solvent of ethylene carbonate (EC) and diethyl carbonate (DEC) in volume ratio of 1:1, is the most commonly used in Li-ion batteries. However, it was proposed inappropriate for Li-S batteries, due to the chemical reaction between nucleophilic sulfide anions and carbonates to form methylated thiolate and thioether during discharge (Gao et al., 2011). Similar results were also confirmed by other groups (Barchasz et al., 2013a; Yim et al., 2013).

In sharp contrast, several studies showed that carbonatebased electrolytes are possible for use in $\mathrm{Li}-\mathrm{S}$ cells under certain conditions. Zhang et al. (2010) used $1 \mathrm{M} \mathrm{LiPF}_{6}$ in PC/EC/DEC 
$(1: 4: 5, \mathrm{v} / \mathrm{v} / \mathrm{v})$ as electrolyte for sulfur/carbon spheres composite cathode. The corresponding Li-S cell showed only one lower discharge voltage plateau at around $1.8 \mathrm{~V}$ instead of two voltage plateaus at 2.3 and $2.1 \mathrm{~V}$ in conventional ether-based electrolyte. The authors attributed this potential hysteresis to the encapsulation of sulfur in the narrow micropores of carbon matrix. The composite contained $42 \mathrm{wt} \%$ sulfur presented a long cycle life of 500 cycles with high capacity retention over $80 \%$ due to constrained electrochemical reaction inside the micropores.

Another significant work by Xin et al. (2012) demonstrated a compatibility against carbonate electrolyte by using metastable small sulfur molecules of $\mathrm{S}_{2-4}$. $\mathrm{S}_{2-4}$ were synthesized in the confined space of a conductive microporous carbon (MPC) matrix in purpose of avoiding the generation of unfavorable long-chain PS, which is highly reactive against carbonates. These confined small $\mathrm{S}_{2-4}$ showed a single discharge plateau at $\sim 1.9 \mathrm{~V}$, with a high specific capacity of $1,670 \mathrm{mAh} \mathrm{g}^{-1}$ and an impressive cycling stability of $1,149 \mathrm{mAh} \mathrm{g}^{-1}$ after 200 cycles. On the basis of the above works, Li et al. (2013) investigated the lithiation/delithiation mechanism of $\mathrm{S}_{2-4}$ cathode by comparing the electrochemical performances of the $S_{2-4}$ and $S_{2-4} / S_{8}$ electrodes in ether or carbonated electrolyte. Figure 4 shows the theoretically calculated dimensions of EC and DMC molecules as well as the lithiation processes of sulfur in different pore structures. If the micropores of carbon are small enough to prevent the penetration of the solvent molecules, the lithiation/delithiation of $\mathrm{S}_{2-4}$ occurs through a solid-solid process, which is in consist with the single plateau in discharge potential profile. In such condition, irreversible chemically reactions between the polysulfides are effectively avoided due to the steric hindrance, ensuring a high adaptability to the electrolytes of the confined $\mathrm{S}_{2-4}$. The corresponding cells can exhibit excellent rate capability and cycling stability. Similar results with S/porous carbon composite as cathodes in carbonate electrolyte were also obtained by some other groups with good electrochemical performances (Wang et al., 2002, 2012; Zheng et al., 2014). However, one of the obvious problems of this strategy is the low sulfur loading due to the small pore volume contributed by micropores.

\section{IONIC LIQUID BASED ELECTROLYTES}

Ionic liquids have been considered as promising electrolytes for $\mathrm{Li}-$ $S$ battery due to highly thermal and chemical stability with good ionic conductivity (Armand et al., 2009). These properties ensure Li-S batteries much greater security in terms of avoidance of leakage and gassing, large electrochemical stability window, and high solvent powers. Owing to the absence of highly solvable ethers, the PS dissolution and shuttle effect could be effectively suppressed to maintain a decreased active material loss and high columbic efficiency. However, the main drawbacks of ILs for Li-S battery are higher viscosities than organic liquids and higher cost compared to other conventional organic solvent.

The very first paper using pure ILs as the electrolyte matrix for Li-S cells was reported by Yang's group (Yuan et al., 2006). A novel room temperature IL N-methyl-N-butyl-piperidinium bis(trifluoromethanesulfonyl) imide (PP14-RTIL), supported by 1 M LiTFSI, was used as electrolyte for Li-S battery. This cell exhibited the initial discharge capacity of $1,055 \mathrm{mAh} \mathrm{g}^{-1}$ with a single discharge plateau at $\sim 1.9 \mathrm{~V}$ and over $750 \mathrm{mAh} \mathrm{g}^{-1}$ after 10 cycles.

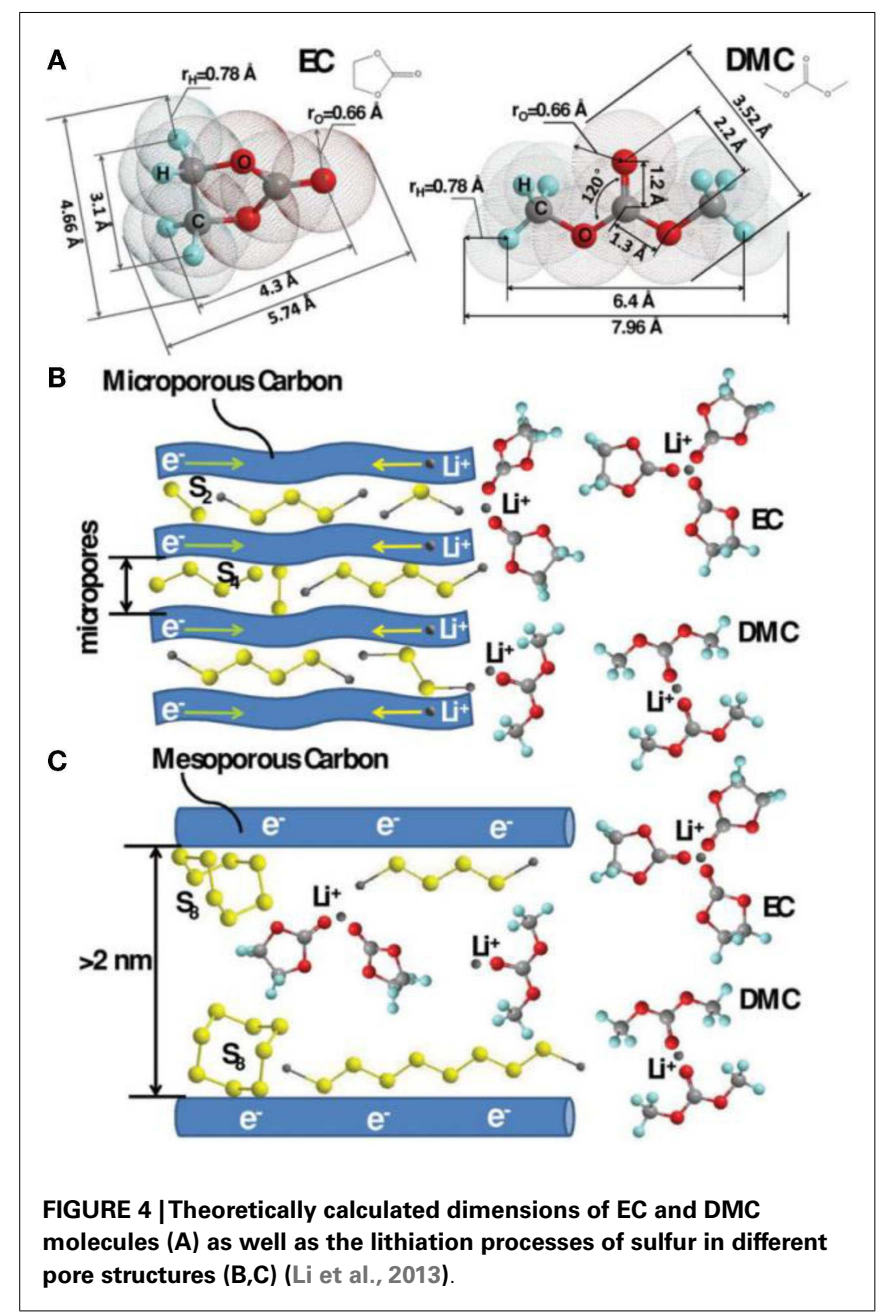

Park et al. (2013a) investigated a Li-S system with a $0.64 \mathrm{M}$ LiTFSI IL electrolyte based on a quaternary ammonia cation N,Ndiethyl-N-methyl-N-(2-methoxyethyl)ammonium (DEME) and TFSI compared with a $0.98 \mathrm{M}$ LiTFSI dissolved in TEGDME electrolyte. The dissolution of PS was significantly suppressed owing to the weak donor ability of [TFSI] $]^{-}$anion. In this IL electrolyte, the electrochemical reduction of sulfur mainly occurred on the surface of electrode through solid phase process, resulting in an improved capacity decay of $\mathrm{Li}-\mathrm{S}$ cells during cycling. Park et al. (2013b) further carried out an extensive work by focusing on the important roles of the IL anions in the electrolytes. The results indicated that the non-ionic sulfur possessed low solubility in all of the evaluated electrolytes, while the $\mathrm{BF}_{4}{ }^{-}$anion and [FS $]^{-}$ anion irreversibly reacts with PS on the surface of electrode. The low-viscosity [TFSI] ${ }^{-}$anion based ILs maintained considerable chemical and electrochemical stability with PS during cycling, allowing the best cell performance with a sustainable capacity up to $>650 \mathrm{mAh} \mathrm{g}^{-1}$ and high coulombic efficiency of $>98 \%$ during 50 cycles.

Wang et al. (2008) compared the behavior of S/mesoporous carbon composite cathode in Li-S cells in $1 \mathrm{M}$ 1-ethyl-3methylimidazolium bis(trifluoromethanesulfonyl)imide (EMIM 
TFSI)/LiTFSI-based electrolyte with $1 \mathrm{M}$ LiTFSI/PEGDME electrolyte. The ILs electrolyte exhibited both better cyclability and discharge capacity due to the claimed less solubility of PS in the IL based electrolyte. More recently, Tachikawa et al. (2011) used a so-called "quasi-IL" [LiG4][NTf2] (G4 = tetraethylene glycol dimethyl ether, TEGDME), a glyme-Li salt molten complex electrolytes, where the $[\mathrm{LiG} 4]^{+}$cation is an equimolar complex of $\mathrm{G} 4$ and $\mathrm{Li}^{+}$. The corresponding cells with sulfur supported on $3 \mathrm{D}$ ordered macroporous carbon as cathode material showed good reversibility, large capacity, and high coulombic efficiency. Yan et al. (2013) reported on an expended selection for IL of [P1A3][TFSI] (P1A3 = n-Methyl-n-Allylpyrrolidinium) by using a Si/C anode instead of metallic lithium. Li-S cells gave a nominal voltage of $1.5 \mathrm{~V}$ and delivered a high initial discharge capacity of $1,457 \mathrm{mAh} \mathrm{g}^{-1}$ at C/10 and remained $670 \mathrm{mAh} \mathrm{g}^{-1}$ after 50 cycles.

Although cyclability of Li-S cells was improved obtained by the employment of IL electrolyte also led to low rate performance and low operation voltage (Shin and Cairns, 2008b). In order to alleviate the above problems, the IL-organic mixture electrolyte was the alternatives to the neat ILs. An early work on IL-organic mixture was conducted by Kim et al. (2005) by introducing different amount imidazolium salt of EMIMBETI and BMIMPF 6 into 0.5 M LiTFSI or 0.5 M LiPF 6 in DOL:DME (1:4 v/v). Best cell performance was obtained when $10 \%$ IL was used. Kim carried out an extended work by using a large number of other ILs as additives in the same DOL:DME (1:4 v/v)-based electrolytes (Kim et al., 2007). The EMI and BMI contained Li-S cells showed much higher capacity and cyclability compared to regular LiTFSI-based Li-S cells due to the lower charge transfer resistance at the electrodes, while DMPI showed poor cell performance probably due to the its irreversible reaction with PS to form a non-conductive coating on the cathode surface.

To sum up, the IL-organic mixture electrolyte combines the advantage of high conductivity in organic solvent and low PS dissolution in ILs. The existence of organic solvent was also designed for decrease of electrolyte viscosity, better wettability, and higher conductivity for better electrochemical kinetics of active sulfur. Based on these beneficial properties, the IL-organic mixture has been considered as a promising electrolyte for Li-S batteries (Shin and Cairns, 2008a; Dokko et al., 2013; Wang and Byon, 2013).

\section{SOLID-STATE ELECTROLYTES}

Though the organic liquid electrolytes dominate Li-S batteries, it is still necessary to search for other electrolytes because of the polysulfide shuttle and the lithium dendrite formation. Under this circumstance, solid electrolytes are considered highly effective in improving Li-S cells performance (Scheers et al., 2014). Figure 5 shows the typical discharge profile in all-solid Li-S batteries. Compared to the typical two plateaus in organic liquid electrolyte, all-solid Li-S cell demonstrates a single plateau at a relatively low potential of around $1.9 \mathrm{~V}$, which is due to the solidsolid single phase reduction from $\mathrm{S}_{8}$ to $\mathrm{Li}_{2} \mathrm{~S}$ with a deteriorated reaction kinetics and polarization.

\section{SOLID POLYMER ELECTROLYTES}

Solid polymer electrolyte is defined as the membrane that possess ion transporting ability compared with the dissociation of lithium

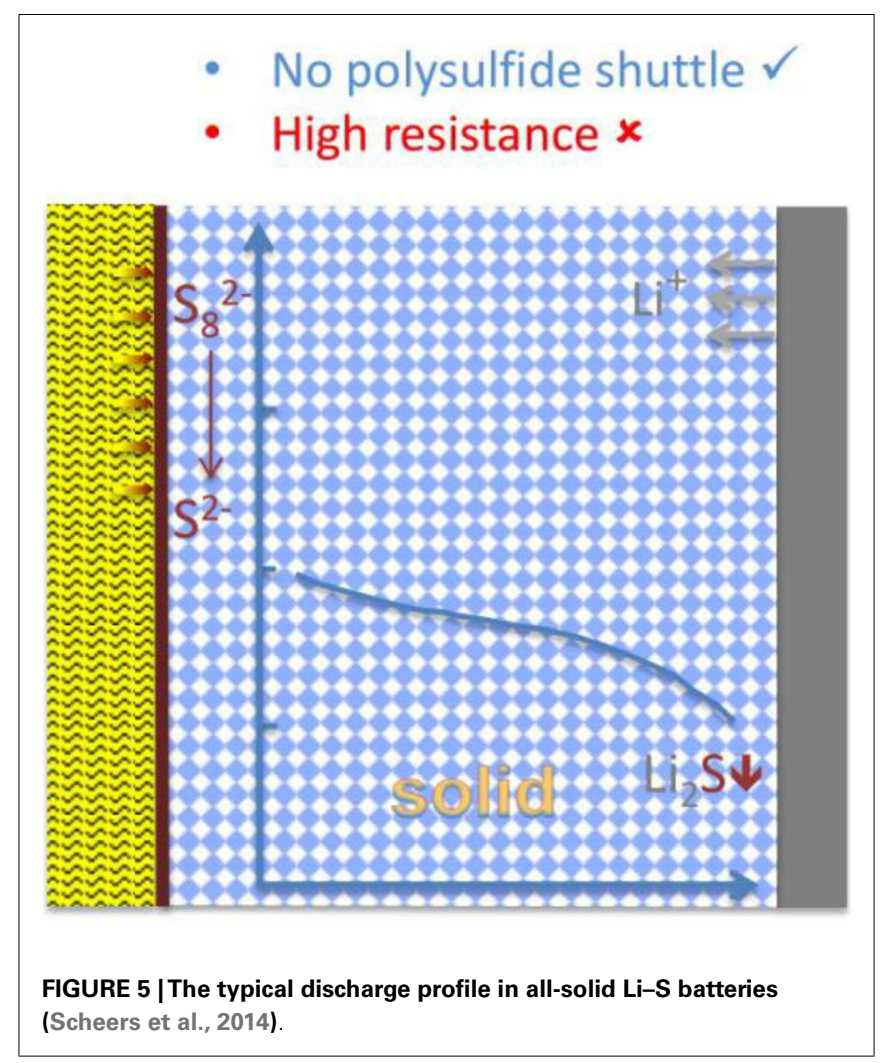

salts in common liquid electrolytes (Manuel Stephan, 2006). Polymer electrolyte has received many attentions after first report by Fenton et al. (1973), mainly due to advantageous properties of no internal shorting, no leakage of electrolytes, non-flammability as well as its promising applications in electrochemical devices (Idris et al., 2012).

The solid polymer electrolyte (SPE) is usually composed of lithium salts dissolved in high molecular weight polymer host, which functionalized as solid solvents (Song et al., 1999). By employing an SPE to assemble all-solid Li-S cells, SPE can effectively suppress the dissolution and diffusion of PS as well as the shuttle phenomenon, greatly enhancing the cyclability of $\mathrm{Li}-\mathrm{S}$ cells (Kim et al., 2006). Many polymers, including poly(ethylene oxide) (PEO), PPO, PAN, PMMA, PVC, poly(vinylidene fluoride) (PVDF), and poly(vinylidene fluoride)-hexafluoropropylene (PVDF-HFP) were adopted as the solid host due to high solvation power and considerable ion transport ability. Among which, PEObased SPE emerged as possibly the best candidate because its great solvation power, complexation ability, and ion transport mechanism directly connected with the alkaline lithium salt (Zhao et al., 2012). Different lithium salts (e.g., $\mathrm{LiClO}_{4}, \mathrm{LiTFSI}, \mathrm{LiBF}_{4}$, and $\mathrm{LiPF}_{6}$ ) were employed to combined with $\mathrm{PEO}$, and their influence on electrolyte ion conductivity is listed in Table $\mathbf{2}$ (Weston and Steele, 1982).

The combination of $\mathrm{PEO}-\mathrm{LiClO}_{4}$ was first studied by Jeon et al. (2003) as electrolyte for Li-S cells. However, the low ionic conductivity of PEO-LiX electrolyte at room temperature $\left(10^{-7}-10^{-6} \mathrm{~S}\right.$ $\mathrm{cm}^{-1}$ ) is inadequate for the application in Li-S cells. Regarding to this problem, recently a promising strategy is to use inorganic 
Table 2 | Lithium-ion conductivity of the PEO-Li $\mathrm{C}_{\mathrm{x}} \mathrm{CPEs}$.

\begin{tabular}{|c|c|c|c|}
\hline Electrolytes & $\begin{array}{l}\text { Conductivity } \\
\left(\mathrm{S} \mathrm{cm}^{-1}\right)\end{array}$ & $\begin{array}{c}\text { Temperature } \\
\left({ }^{\circ} \mathrm{C}\right)\end{array}$ & Reference \\
\hline PEO-LiBF 4 & $1.12 \times 10^{-4}$ & 90 & Shin et al. (2002b) \\
\hline PEO-LiPF 6 & $2.69 \times 10^{-4}$ & 90 & \\
\hline $\mathrm{PEO}-\mathrm{LiCF}_{3} \mathrm{SO}_{3}$ & $8.38 \times 10^{-5}$ & 90 & \\
\hline PEO-LiCF $\mathrm{SO}_{3}-10 \mathrm{wt} \%$ & $1.80 \times 10^{-4}$ & 90 & \\
\hline $\mathrm{TinO}_{2 \mathrm{n}-1}$ & & & \\
\hline $\begin{array}{l}\mathrm{PEO}-\mathrm{LiCF}_{3} \mathrm{SO}_{3} \mathrm{Li}_{2} \\
\mathrm{~S}-10 \mathrm{wt} \% \mathrm{ZrO}_{2}\end{array}$ & $10^{-4} \sim 10^{-3}$ & 70 & Liang et al. (2011) \\
\hline $\begin{array}{l}\text { PEO-Li( }\left(\mathrm{CF}_{3} \mathrm{SO}_{2}\right)_{2} \\
\mathrm{~N}-10 \mathrm{wt} \% \mathrm{SiO}_{2}\end{array}$ & $5 \times 10^{-4}$ & 70 & Liang et al. (2011) \\
\hline PEO-LiPF $6-10 w t \% \mathrm{TiO}_{2}$ & $2 \times 10^{-5}$ & 25 & Ahn et al. (2003) \\
\hline $\begin{array}{l}\text { PEO-LiClO } \\
4-10 ~ w t \% \\
\mathrm{Al}_{2} \mathrm{O}_{3}\end{array}$ & $2.5 \times 10^{-5}$ & 25 & \\
\hline
\end{tabular}

ceramic filler such as $\mathrm{SiO}_{2}, \mathrm{TiO}_{2}, \mathrm{ZrO}_{2}, \mathrm{Al}_{2} \mathrm{O}_{3}$, and $\mathrm{LiAlO}_{2}$ in the host polymer matrix to enhance the ionic conductivity of SPEs (Appetecchi et al., 2000; Chung et al., 2001; Croce et al., 2001; Shin et al., 2002b; Ahn et al., 2003; Dissanayake et al., 2003; Lin et al., 2005; Zhu et al., 2005; Jeong et al., 2007). The nano-filler is beneficial to reduce the crystallinity of polymer solvent so as to the increase of ion conductivity due to the amorphous phase. Additionally, the filler surface groups interact with the PEO oxygen atoms and the crosslinking polymer chains retard the structural reorganizations and increase the Li-ion mobility (Przyluski et al., 1995).

One significant work was carried out by Hassoun et al. by using $\mathrm{ZrO}_{2}$ as an electrolyte additive for $\mathrm{Li}-\mathrm{S}$ batteries (Hassoun and Scrosati, 2010b). With $10 \mathrm{wt} \% \mathrm{ZrO}_{2}$, significant enhancements in ion conductivity, $\mathrm{Li}^{+}$transference number, and electrode/electrolyte interface stability were obtained as well as the formation of finely dispersed layer on lithium surface (Croce et al., 2006a,b). The corresponding Li-S cells maintained a capacity up to $900 \mathrm{mAh} \mathrm{g}^{-1}$ and a sustained high coulombic efficiency close to $100 \%$ for 50 cycles. Liang et al. (2011) studied PEO 18 LiTFSI-10 $\mathrm{wt} \% \mathrm{SiO}_{2}$ as electrolyte with a mesoporous carbon sphere with uniform channels (OMCs) supported sulfur as the cathode. The $\mathrm{Li}-\mathrm{S}$ cells exhibited excellent cycling performance with a reversible capacity up to $800 \mathrm{mAh} \mathrm{g}^{-1}$ after 25 cycles.

Though the SPE was successfully optimized by inorganic additives, the rate performance still remains poor (usually no higher than $\mathrm{C} / 20$ ), and a relatively high temperature is needed for adequate ion conductivity.

\section{GEL POLYMER ELECTROLYTES}

The gel polymer electrolyte (GPE), where the liquid component is tightly trapped in the polymer matrix, was developed as a compromise strategy against the low ionic conductivity of SPE (Xu and Ye, 2005). The bulk of the membrane was usually composed of connected micropores to ensure adequate absorption amount toward liquid electrolyte. The ion conductivity is largely depended on the property of liquid electrolyte or otherwise the transfer of $\mathrm{Li}^{+}$ mainly happens in the polymer membrane with insufficient liquid absorption (Li et al., 2008). Several types of polymer membranes, such as those based on PEO, PVDF, and PVDF-HFP, were developed and characterized for Li-S cells (Shin et al., 2002a; Wang et al., 2002, 2003; Ryu et al., 2006; Hassoun and Scrosati, 2010a; Zhang and Tran, 2013).

Ryu et al. (2006) used PVDF based polymer matrix combined with LiTf/tetraglyme as electrolyte for Li-S cells. Two plateaus were observed in the first discharge possessing a high capacity up to $1,268 \mathrm{mAh} \mathrm{g}^{-1}$. However, the upper plateau disappeared in the second discharge with a deceased capacity of $1,028 \mathrm{mAh} \mathrm{g}^{-1}$, indicating the hindering effect of GPE in the dissolution of long-chain PS. Hassoun and Scrosati (2010a) made in important progress by building a metallic lithium-free system using $\mathrm{Sn} / \mathrm{C}$ anode and $\mathrm{Li}_{2} \mathrm{~S} / \mathrm{C}$ cathode. Gel-type polymer membrane formed by trapping $\mathrm{LiPF}_{6} / \mathrm{EC}+\mathrm{DMC}$ in $\mathrm{PEO} / \mathrm{LiCF}_{3} \mathrm{SO}_{3}$ polymer matrix was adopted as electrolyte with dispersed zirconia ceramic filer as additive to enhance the mechanical property. Impedance study indicated a low resistance and a high conductivity close to $10^{-2} \mathrm{~S} \mathrm{~cm}^{-1}$. The obtained polymer cell showed a high initial capacity of over $1,200 \mathrm{mAh} \mathrm{g}^{-1}$ and good capacity retention at $\mathrm{C} / 20$ rate along with cycling. The GPE functionalized as the barrier to prevent PS dissolution, and the $\mathrm{Sn} / \mathrm{C}$ anode aimed to eliminate the risk of anode corrosion for liquid electrolyte.

Owing to the combination of SPE and liquid electrolyte, higher ion conductivity, and better reaction kinetics were obtained by GPE at the cost of the resurgence of PS dissolution and shuttle effect. However, more deep going and systematic research on how GPE and GPE composition affects the PS solvation characteristic as well as modification on pore structure and polymer crystallinity in purpose of improved $\mathrm{Li}^{+}$transport remain to be carried out.

\section{NON-POLYMER ELECTROLYTES}

In virtue of the poor cell performance with solid polymer based electrolytes, non-polymer electrolytes provide a promising strategy for all-solid Li-S cells considering its inherent advantages of high thermal and chemical stability toward the Li anode under ambient atmosphere (Adachi et al., 1996; Robertson et al., 1997; Thangadurai and Weppner, 2006; Thangadurai et al., 2014). Since the first study on primary solid-state Li-ion batteries in 1972 (Scrosati, 1972), large number of inorganic solid-state electrolytes were investigated for $\mathrm{Li}-\mathrm{S}$ cells as well as $\mathrm{Li}$-ion batteries, including LiSICON-type phosphates, perovskite-type $\left.\mathrm{La}_{(2 / 3)}\right)_{\mathrm{x}} \mathrm{Li}_{3 \mathrm{x}} \mathrm{TiO}_{3}$ (LLT), $\mathrm{Li}_{3} \mathrm{~N}$, and $\mathrm{Li}_{4} \mathrm{SiO}_{4}$ (Hayashi et al., 2003b; Stramare et al., 2003; Kobayashi et al., 2008; Nagao et al., 2011, 2013). A list of non-polymer electrolytes, comparing with other electrolytes including polymer electrolytes, ionic liquids, and gel electrolytes, are shown in Figure 6.

The family of sulfide compounds that form amorphous solid electrolyte with high $\mathrm{Li}^{+}$conductivity is one of the hotspot in inorganic solid-state electrolytes. The group of Hayashi and Tatsumisago carried out a series of significant works on $\mathrm{Li}_{2} \mathrm{~S}$ $\mathrm{P}_{2} \mathrm{~S}_{5}$ glass electrolyte (Hayashi et al., 2001b, 2004, 2008; Nagao et al., 2012; Teragawa et al., 2014). In their early work, mechanical milled $80 \mathrm{Li}_{2} \mathrm{~S}-20 \mathrm{P}_{2} \mathrm{~S}_{5}(\mathrm{~mol} \%)$ glass was demonstrated of an exceptionally high conductivity up to $10^{-3} \mathrm{~S} \mathrm{~cm}^{-1}$ at room temperature, due to the formation of $\mathrm{Li}_{7} \mathrm{PS}_{6}$ (Hayashi et al., 2001a), which was described as "superionic" and crystallographic analogs of thio-LISICON (Hayashi et al., 2003a). The $\mathrm{Li}_{2} \mathrm{~S}_{-} \mathrm{P}_{2} \mathrm{~S}_{5}$ 


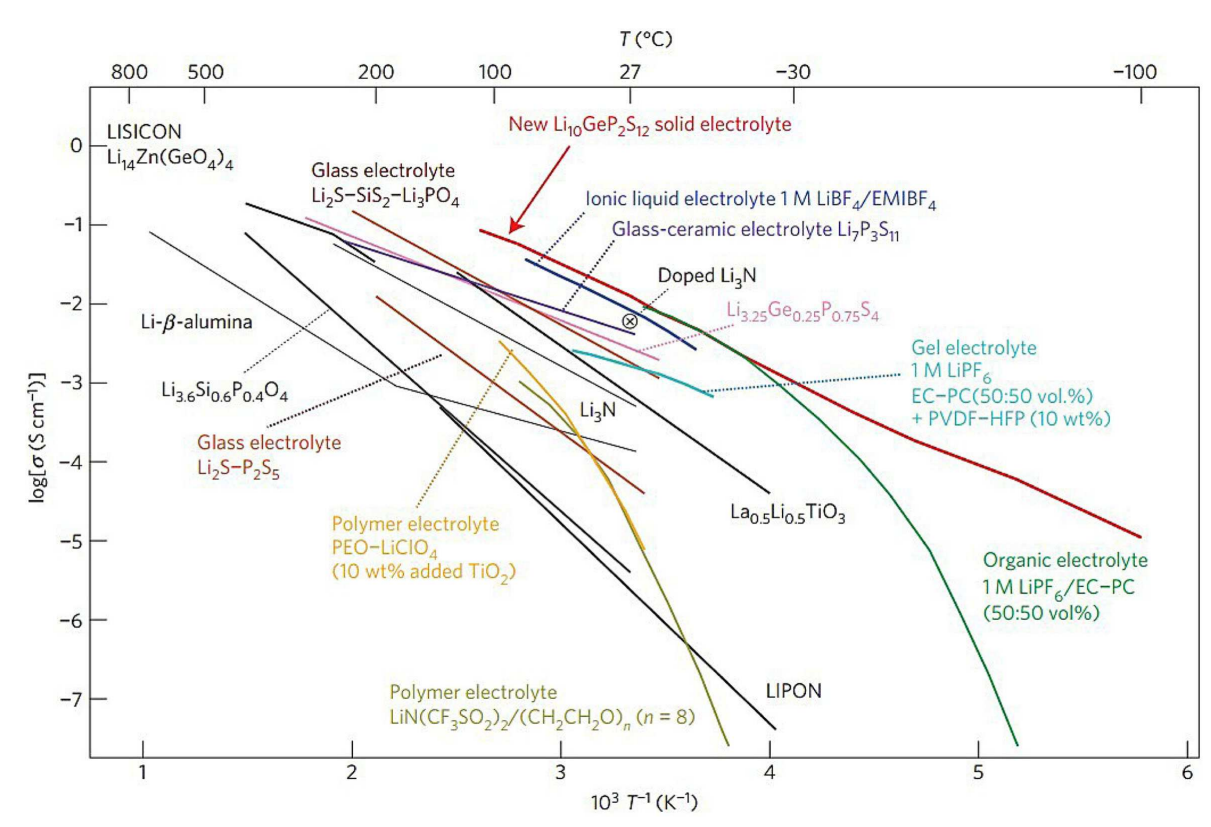

FIGURE 6 |Thermal evolution of ionic conductivity of the $\mathrm{Li}_{10} \mathrm{GeP}_{2} \mathrm{~S}_{12}$ phase, together with those of other lithium solid electrolytes, polymer electrolytes, ionic liquids, and gel electrolytes (Kamaya et al., 2011).

glass-ceramic electrolyte was successfully applied in Li-S system. The corresponding cells with S/CuS cathode retained capacity of over $650 \mathrm{mAhg}^{-1}$ for 20 cycles (Hayashi et al., 2003b). Further development was obtained by using sulfur-carbon composite electrode and $\mathrm{Li}_{2} \mathrm{~S}-\mathrm{P}_{2} \mathrm{~S}_{5}$ glass-ceramic electrolyte. Excellent cell performance was maintained with reversible capacity over $850 \mathrm{mAh} \mathrm{g}^{-1}$ for 200 charge/discharge cycles under $1.3 \mathrm{~mA} \mathrm{~cm}^{-2}$ at room temperature, and even close to $500 \mathrm{mAh} \mathrm{g}^{-1}$ at $20 \mathrm{~mA} \mathrm{~g}^{-1}$ when temperature was raised to $80^{\circ} \mathrm{C}$ (Nagao et al., 2011). Recently, a related compound of $\mathrm{Li}_{10} \mathrm{GeP}_{2} \mathrm{~S}_{12}$ developed by Kamaya et al. (2011) shows an ever highest ion conductivity of around $10^{-2} \mathrm{~S}$ $\mathrm{cm}^{-1}$ at room temperature with good potential of application in Li-S system, albeit that the relatively limited reversibility against metallic lithium remains to be overcome. Nagata el al. assembled cells using Li-In alloy as negative electrode and $\mathrm{Li}_{10} \mathrm{GeP}_{2} \mathrm{~S}_{12}$ as solid electrolyte (Nagata and Chikusa, 2014). The cathode material was prepared by mechanochemical treatment on the mixture of $\mathrm{Li}_{1.5} \mathrm{PS}_{3.3}$, sulfur, and conductive carbon. The resulting cathode showed the reversible capacity of $1,600 \mathrm{mAh} \mathrm{g}^{-1}$ (based on sulfur) after 100 cycles under $1^{\circ} \mathrm{C}$ rate at $25^{\circ} \mathrm{C}$, exhibiting a high power density of over $11,000 \mathrm{~W} \mathrm{~kg}^{-1}$ at $50 \%$ SOC.

Recently, the Liang's group at Oak Ridge National Laboratory reported a nanoporous $\beta-\mathrm{Li}_{3} \mathrm{PS}_{4}$ with high conductivity up to $1.6 \times 10^{-4} \mathrm{~S} \mathrm{~cm}^{-1}$ at room temperature through a liquid-state reaction (Liu et al., 2013). Reversible lithium deposition and excellent inhabitation against lithium dendrite were identified by $\mathrm{CV}$ and cells cycling at $25^{\circ} \mathrm{C}$. In the subsequent development of this material, nano-sized $\mathrm{Li}_{2} \mathrm{~S}$ particles coated by $\beta-\mathrm{Li}_{3} \mathrm{PS}_{4}$ were prepared as the active material for cathode (Lin et al., 2013b). With the thiophosphate also serving as the electrolyte, metallic lithium as anode, the assembled cells delivered a considerable capacity of
$1,216 \mathrm{mAh}^{-1}$ (based on sulfur) in the first discharge, but also suffered about $30 \%$ capacity decay over 100 cycles at $60^{\circ} \mathrm{C}$. It should be noted that the low surface area carbon used in this work may result in a lack of extensive interaction between sulfur/sulfide and functional substrate. Another application of this material is in the form of $\mathrm{P}_{2} \mathrm{~S}_{5}$ additive toward the conventional liquid electrolyte by forming $\beta-\mathrm{Li}_{3} \mathrm{PS}_{4}$ on electrolyte surfaces, providing good ion transporting, protection anode from PS and raised solubility for all sulfides as mentioned in liquid electrolyte additive part. Lin et al. (2013c) made a significant progress by using a novel class of sulfur-rich lithium polysulfidophosphates as cathodes for $\mathrm{Li}-\mathrm{S}$ battery. These compounds exhibited a high Li-ion conductivity of $10^{-4}-10^{-5} \mathrm{~S} \mathrm{~cm}^{-1}$ at room temperature. Excellent performance was demonstrated when this cathode material was combined with the solid-state $\mathrm{Li}_{3} \mathrm{PS}_{4}$ electrolyte to display a reversible capacity of over $1,200 \mathrm{mAh} \mathrm{g}^{-1}$ at $\mathrm{C} / 10$ over 300 cycles at $60^{\circ} \mathrm{C}$.

\section{CONCLUSION AND PROSPECTS}

Though promising, the tough challenges of the insulating properties of sulfur species, the polysulfide shuttle, and the dendrite formation/safety concerns have prevented the Li-S batteries from practical applications. In the past few years, significant efforts have been dedicated to the study of each component in the Li-S cells for improved cyclability. In this article, we have reviewed the most recent progresses in $\mathrm{Li}-\mathrm{S}$ batteries in the field of electrolyte systems, including liquid electrolytes and solid electrolytes.

As the most commonly used electrolyte, liquid electrolytes are chosen because of its high ion conductivity, low-viscosity, and high compatibility with lithium and PS. There's indeed a large variation in the properties of electrolytes with different solvents, salts, and additives. As the emergence of different cathode materials and 
designs, electrolyte should be uniquely defined for each system in purpose of better performance. In the future research, liquid electrolytes need to be compared and studied systematically in the following aspects: (1) understanding the cycling mechanisms when different electrolytes are used, (2) implementing alternative electrolytes in the same Li-S cell configuration to study the importance of each component, (3) having better understanding of PS behavior and anode SEI formation using different electrolytes, and (4) choosing the suitable liquid electrolyte for the Li-S battery system.

With the emergence of solid electrolytes with ionic conductivities comparable to that of liquid electrolytes, the all-solid Li-S batteries promise to be the next breakthrough for electric energy storage. The replacement of liquid electrolytes by solid electrolyte eliminates the polysulfide shuttle and enables the practical applications of high-energy and intrinsically safe Li-S batteries. For the future research, solid electrolytes need to be compared and studied systematically in the following aspects: (1) the ionic conductivities of SPEs and GPEs need to be enhanced for further applications, (2) the electrochemical mechanisms of the Li-S cells need to be studied further when solid electrolytes are used, (3) novel electrolyte compositions or good additives should be explored to improve stability and solve safety concerns when cycling metallic lithium anodes, and (4) interfacial resistance need to be solved for high-performance all-solid Li-S cells.

In summary, Li-S batteries can supply the theoretical energy density five times higher than that of Li-ion batteries, and they have been considered as the most promising candidate for the application in the electrification of vehicles. With great interest and extensive research in the Li-S cells, there have been significant progresses in improving cycling performance of both liquid and solid Li-S batteries. With more and more developments in this field, we believe that Li-S batteries could be a practical technology for the applications in transportation and large-scale grid energy storage in the near future.

\section{ACKNOWLEDGMENTS}

This work is financially supported by the National Natural Science Foundation of China, Grant No. 21476200 and 21276229; the Zhejiang Provincial Natural Science Foundation of China, Grant No. Z4110126.

\section{REFERENCES}

Adachi, G. Y., Imanaka, N., and Aono, H. (1996). Fast Li-circle plus conducting ceramic electrolytes. Adv. Mater. 8, 127-135. doi:10.1002/adma.19960080205

Ahn, J. H., Wang, G. X., Liu, H. K., and Dou, S. X. (2003). Nanoparticle-dispersed PEO polymer electrolytes for Li batteries. J. Power Sources 119, 422-426. doi:10.1016/S0378-7753(03)00264-7

Appetecchi, G. B., Croce, F., Persi, L., Ronci, F., and Scrosati, B. (2000). Transport and interfacial properties of composite polymer electrolytes. Electrochim. Acta 45, 1481-1490. doi:10.1016/S0013-4686(99)00363-1

Armand, M. (1994). The history of polymer electrolytes. Solid State Ionics 69, 309-319. doi:10.1016/0167-2738(94)90419-7

Armand, M., Endres, F., Macfarlane, D. R., Ohno, H., and Scrosati, B. (2009). Ionicliquid materials for the electrochemical challenges of the future. Nat. Mater. 8, 621-629. doi:10.1038/nmat2448

Aurbach, D., Pollak, E., Elazari, R., Salitra, G., Kelley, C. S., and Affinito, J. (2009). On the surface chemical aspects of very high energy density, rechargeable Li-sulfur batteries. J. Electrochem. Soc. 156, A694. doi:10.1149/1.3148721
Aurbach, D., Youngman, O., and Dan, P. (1990a). The electrochemical-behavior of 1,3-dioxolane-LiCLO4 solutions. 2. Contaminated solutions. Electrochim. Acta 35, 639-655. doi:10.1016/0013-4686(90)87056-8

Aurbach, D., Youngman, O., Gofer, Y., and Meitav, A. (1990b). The electrochemicalbehavior of 1,3-dioxolane-LiCLO4 solutions. 1. Uncontaminated solutions. Electrochim. Acta 35, 625-638. doi:10.1016/0013-4686(90)87055-7

Barchasz, C., Lepretre, J. C., Patoux, S., and Alloin, F. (2013a). Electrochemical properties of ether-based electrolytes for lithium/sulfur rechargeable batteries. Electrochim. Acta 89, 737-743. doi:10.1016/j.electacta.2012.11.001

Barchasz, C., Lepretre, J. C., Patoux, S., and Alloin, F. (2013b). Revisiting TEGDME/DIOX binary electrolytes for lithium/sulfur batteries: importance of solvation ability and additives. J. Electrochem. Soc. 160, A430-A436. doi:10.1149/ 2.022303jes

Barchasz, C., Mesguich, F., Dijon, J., Lepretre, J. C., Patoux, S., and Alloin, F. (2012a). Novel positive electrode architecture for rechargeable lithium/sulfur batteries. J. Power Sources 211, 19-26. doi:10.1016/j.jpowsour.2012.03.062

Barchasz, C., Molton, F., Duboc, C., Lepretre, J. C., Patoux, S., and Alloin, F. (2012b). Lithium/sulfur cell discharge mechanism: an original approach for intermediate species identification. Anal. Chem. 84, 3973-3980. doi:10.1021/ac2032244

Barghamadi, M., Kapoor, A., and Wen, C. (2013). A review on Li-S batteries as a high efficiency rechargeable lithium battery. J. Electrochem. Soc. 160, A1256-A1263. doi:10.1149/2.096308jes

Bresser, D., Passerini, S., and Scrosati, B. (2013). Recent progress and remaining challenges in sulfur-based lithium secondary batteries - a review. Chem. Commun. (Camb.) 49, 10545-10562. doi:10.1039/c3cc46131a

Chen, L., and Shaw, L. L. (2014). Recent advances in lithium-sulfur batteries. J. Power Sources 267, 770-783. doi:10.1016/j.jpowsour.2014.05.111

Choi, J.-W., Kim, J.-K., Cheruvally, G., Ahn, J.-H., Ahn, H.-J., and Kim, K.-W. (2007). Rechargeable lithium/sulfur battery with suitable mixed liquid electrolytes. Electrochim. Acta 52, 2075-2082. doi:10.1016/j.electacta.2006.08.016

Chung, S. H., Wang, Y., Persi, L., Croce, F., Greenbaum, S. G., Scrosati, B., et al (2001). Enhancement of ion transport in polymer electrolytes by addition of nanoscale inorganic oxides. J. Power Sources 9, 644-648. doi:10.1016/S03787753(01)00748-0

Croce, F., Persi, L., Scrosati, B., Serraino-Fiory, F., Plichta, E., and Hendrickson, M. A. (2001). Role of the ceramic fillers in enhancing the transport properties of composite polymer electrolytes. Electrochim. Acta 46, 2457-2461. doi:10.1016/S0013-4686(01)00458-3

Croce, F., Sacchetti, S., and Scrosati, B. (2006a). Advanced, high-performance composite polymer electrolytes for lithium batteries. J. Power Sources 161, 560-564. doi:10.1016/j.jpowsour.2006.03.069

Croce, F., Settimi, L., and Scrosati, B. (2006b). Superacid ZrO2-added, composite polymer electrolytes with improved transport properties. Electrochem. Commun. 8, 364-368. doi:10.1016/j.elecom.2005.12.002

Demir-Cakan, R., Morcrette, M., Gangulibabu, B., Guéguen, A., Dedryvère, R., and Tarascon, J.-M. (2013). Li-S batteries: simple approaches for superior performance. Energy Environ. Sci. 6, 176-182. doi:10.1039/c2ee23411d

Dissanayake, M. A. K. L., Jayathilaka, P. A. R. D., Bokalawala, R. S. P., Albinsson, I., and Mellander, B.-E. (2003). Effect of concentration and grain size of alumina filler on the ionic conductivity enhancement of the (PEO)9LiCF3SO3:Al2O3 composite polymer electrolyte. J. Power Sources 119-121, 409-414. doi:10.1016/ s0378-7753(03)00262-3

Dokko, K., Tachikawa, N., Yamauchi, K., Tsuchiya, M., Yamazaki, A., Takashima, E., et al. (2013). Solvate ionic liquid electrolyte for Li-S batteries. J. Electrochem. Soc. 160, A1304-A1310. doi:10.1149/2.111308jes

Dudley, J. T., Wilkinson, D. P., Thomas, G., Levae, R., Woo, S., Blom, H., et al. (1991). Conductivity of electrolytes for rechargeable lithium batteries. J. Power Sources 35, 59-82. doi:10.1016/0378-7753(91)80004-H

Ellis, B. L., Lee, K. T., and Nazar, L. F. (2010). Positive electrode materials for Li-ion and Li-batteries ${ }^{\dagger}$. Chem. Mater. 22, 691-714. doi:10.1021/cm902696j

Etacheri, V., Marom, R., Elazari, R., Salitra, G., and Aurbach, D. (2011). Challenges in the development of advanced Li-ion batteries: a review. Energy Environ. Sci. 4, 3243. doi:10.1039/clee01598b

Evers, S., and Nazar, L. F. (2013). New approaches for high energy density lithiumsulfur battery cathodes. Acc. Chem. Res. 46, 1135-1143. doi:10.1021/ar3001348

Fenton, D. E., Parker, J. M., and Wright, P. V. (1973). Complexes of alkali-metal ions with poly(ethylene oxide). Polymer 14, 589-589. doi:10.1016/0032-3861(73) 90146-8 
Foropoulos, J., and Desmarteau, D. D. (1984). Synthesis, properties, and reactions of bis((trifluoromethyl)sulfonyl) imide, (Cf3so2)2nh. Inorg. Chem. 23, 3720-3723. doi:10.1021/Ic00191a011

Gao, J., Lowe, M. A., Kiya, Y., and Abruña, H. D. (2011). Effects of liquid electrolytes on the charge-discharge performance of rechargeable lithium/sulfur batteries: electrochemical and in-situ X-ray absorption spectroscopic studies. J. Phys. Chem. C 115, 25132-25137. doi:10.1021/jp207714c

Gofer, Y., Ely, Y. E., and Aurbach, D. (1992). Surface-chemistry of lithium in 1,3dioxolane. Electrochim. Acta 37, 1897-1899. doi:10.1016/0013-4686(92)85096-4

Goodenough, J. B., and Kim, Y. (2010). Challenges for rechargeable Li batteries ${ }^{\dagger}$. Chem. Mater. 22, 587-603. doi:10.1021/cm901452z

Guerfi, A., Duchesne, S., Kobayashi, Y., Vijh, A., and Zaghib, K. (2008). LiFePO4 and graphite electrodes with ionic liquids based on bis(fluorosulfonyl)imide (FSI)(-) for Li-ion batteries. J. Power Sources 175, 866-873. doi:10.1016/j.jpowsour.2007. 09.030

Hassoun, J., and Scrosati, B. (2010a). A high-performance polymer tin sulfur lithium ion battery. Angew. Chem. Int. Ed. Engl. 49, 2371-2374. doi:10.1002/ anie. 200907324

Hassoun, J., and Scrosati, B. (2010b). Moving to a solid-state configuration: a valid approach to making lithium-sulfur batteries viable for practical applications. Adv. Mater. 22, 5198-5201. doi:10.1002/adma.201002584

Hayashi, A., Hama, S., Minami, T., and Tatsumisago, M. (2003a). Formation of superionic crystals from mechanically milled Li2S-P2S5 glasses. Electrochem. Commun. 5, 111-114. doi:10.1016/S1388-2481(02)00555-6

Hayashi, A., Ohtomo, T., Mizuno, F., Tadanaga, K., and Tatsumisago, M. (2003b). All-solid-state Li/S batteries with highly conductive glass-ceramic electrolytes. Electrochem. Commun. 5, 701-705. doi:10.1016/s1388-2481(03) 00167-x

Hayashi, A., Hama, S., Morimoto, H., Tatsumisago, M., and Minami, T. (2001a). High lithium ion conductivity of glass-ceramics derived from mechanically milled glassy powders. Chem. Lett. 84, 872-873. doi:10.1246/cl.2001.872

Hayashi, A., Hama, S., Morimoto, H., Tatsumisago, M., and Minami, T. (2001b). Preparation of Li2S-P2S5 amorphous solid electrolytes by mechanical milling. J. Am. Ceram. Soc. 84, 477-479. doi:10.1111/j.1151-2916.2001. tb00685.x

Hayashi, A., Ohtomo, T., Mizuno, F., Tadanaga, K., and Tatsumisago, M. (2004). Rechargeable lithium batteries, using sulfur-based cathode materials and Li2SP2S5 glass-ceramic electrolytes. Electrochim. Acta 50, 893-897. doi:10.1016/j. electacta.2004.02.061

Hayashi, A., Ohtsubo, R., Ohtomo, T., Mizuno, F., and Tatsumisago, M. (2008). All-solid-state rechargeable lithium batteries with Li2S as a positive electrode material. J. Power Sources 183, 422-426. doi:10.1016/j.jpowsour.2008. 05.031

Idris, N. H., Rahman, M. M., Wang, J. Z., and Liu, H. K. (2012). Microporous gel polymer electrolytes for lithium rechargeable battery application. J. Power Sources 201, 294-300. doi:10.1016/j.jpowsour.2011.10.141

Jeon, B. H., Yeon, J. H., and Chung, I. J. (2003). Preparation and electrical properties of lithium-sulfur-composite polymer batteries. J. Mater. Process. Technol. 143, 93-97. doi:10.1016/S0924-0136(03)00327-3

Jeong, S. S., Lim, Y. T., Choi, Y. J., Cho, G. B., Kim, K. W., Ahn, H. J., et al. (2007). Electrochemical properties of lithium sulfur cells using PEO polymer electrolytes prepared under three different mixing conditions. J. Power Sources 174, 745-750. doi:10.1016/j.jpowsour.2007.06.108

Ji, X., and Nazar, L. F. (2010). Advances in Li-S batteries. J. Mater. Chem. 20, 9821. doi:10.1039/b925751a

Kamaya, N., Homma, K., Yamakawa, Y., Hirayama, M., Kanno, R., Yonemura, M., et al. (2011). A lithium superionic conductor. Nat. Mater. 10, 682-686. doi: $10.1038 /$ nmat3066

Kim, H.-S., and Jeong, C.-S. (2011). Electrochemical properties of binary electrolytes for lithium-sulfur batteries. Bull. Korean Chem. Soc. 32, 3682-3686. doi:10.5012/bkcs.2011.32.10.3682

Kim, K. M., Park, N. G., Ryu, K. S., and Chang, S. H. (2006). Characteristics of PVdF-HFP/TiO2 composite membrane electrolytes prepared by phase inversion and conventional casting methods. Electrochim. Acta 51, 5636-5644. doi:10.1016/j.electacta.2006.02.038

Kim, S., Jung, Y., and Park, S.-J. (2005). Effects of imidazolium salts on discharge performance of rechargeable lithium-sulfur cells containing organic solvent electrolytes. J. Power Sources 152, 272-277. doi:10.1016/j.jpowsour.2005. 03.003
Kim, S., Jung, Y., and Park, S. J. (2007). Effect of imidazolium cation on cycle life characteristics of secondary lithium-sulfur cells using liquid electrolytes. Electrochim. Acta 52, 2116-2122. doi:10.1016/j.electacta.2006.08.028

Kim, S., Jung, Y. J., and Lim, H. S. (2004). The effect of solvent component on the discharge performance of lithium-sulfur cell containing various organic electrolytes. Electrochim. Acta 50, 889-892. doi:10.1016/j.electacta.2004. 01.093

Kim, T. J., Jeong, B. O., Koh, J. Y., Kim, S., and Jung, Y. (2014). Influence of electrolyte composition on electrochemical performance of Li-S cells. Bull. Korean Chem. Soc. 35, 1299-1304. doi:10.5012/bkcs.2014.35.5.1299

Kobayashi, T., Imade, Y., Shishihara, D., Homma, K., Nagao, M., Watanabe, R. et al. (2008). All solid-state battery with sulfur electrode and thioLISICON electrolyte. J. Power Sources 182, 621-625. doi:10.1016/j.jpowsour. 2008.03.030

Kodama, D., Kanakubo, M., Kokubo, M., Hashimoto, S., Nanjo, H., and Kato, M. (2011). Density, viscosity, and solubility of carbon dioxide in glymes. Fluid Phase Equilib. 302, 103-108. doi:10.1016/j.fluid.2010.08.014

Krause, L. J., Lamanna, W., Summerfield, J., Engle, M., Korba, G., Loch, R., et al. (1997). Corrosion of aluminum at high voltages in non-aqueous electrolytes containing perfluoroalkylsulfonyl imides; new lithium salts for lithium-ion cells. J. Power Sources 68, 320-325. doi:10.1016/S0378-7753(97) 02517-2

Li, G. C., Li, Z. H., Zhang, P., Zhang, H. P., and Wu, Y. P. (2008). Research on a gel polymer electrolyte for Li-ion batteries. Pure Appl. Chem. 80, 2553-2563. doi:10.1351/pac200880112553

Li, H., Wang, Z., Chen, L., and Huang, X. (2009). Research on advanced materials for Li-ion batteries. Adv. Mater. 21, 4593-4607. doi:10.1002/adma. 200901710

Li, Z., Yuan, L., Yi, Z., Sun, Y., Liu, Y., Jiang, Y., et al. (2013). Insight into the electrode mechanism in lithium-sulfur batteries with ordered microporous carbon confined sulfur as the cathode. Advanced Energy Materials 4, 473-477 doi:10.1002/aenm.201301473

Liang, X., Wen, Z., Liu, Y., Zhang, H., Huang, L., and Jin, J. (2011). Highly dispersed sulfur in ordered mesoporous carbon sphere as a composite cathode for rechargeable polymer Li/S battery. J. Power Sources 196, 3655-3658. doi:10.1016/j.jpowsour.2010.12.052

Lin, C. W., Hung, C. L., Venkateswarlu, M., and Hwang, B. J. (2005). Influence of $\mathrm{TiO} 2$ nano-particles on the transport properties of composite polymer electrolyte for lithium-ion batteries. J. Power Sources 146, 397-401. doi:10.1016/j. jpowsour.2005.03.028

Lin, Z., Liu, Z., Fu, W., Dudney, N. J., and Liang, C. (2013a). Phosphorous pentasulfide as a novel additive for high-performance lithium-sulfur batteries. Adv. Funct. Mater. 23, 1064-1069. doi:10.1002/adfm.201200696

Lin, Z., Liu, Z. C., Dudney, N. J., and Liang, C. D. (2013b). Lithium superionic sulfide cathode for all-solid lithium-sulfur batteries. ACS Nano 7, 2829-2833. doi:10.1021/Nn400391h

Lin, Z., Liu, Z. C., Fu, W. J., Dudney, N. J., and Liang, C. D. (2013c). Lithium polysulfidophosphates: a family of lithium-conducting sulfur-rich compounds for lithium-sulfur batteries. Angew. Chem. Int. Ed. 52, 7460-7463. doi:10.1002/anie. 201300680

Liu, Z. C., Fu, W. J., Payzant, E. A., Yu, X., Wu, Z. L., Dudney, N. J., et al. (2013). Anomalous high ionic conductivity of nanoporous beta-Li3PS4. J. Am. Chem. Soc. 135, 975-978. doi:10.1021/Ja3110895

Manthiram, A., Fu, Y., Chung, S. H., Zu, C., and Su, Y. S. (2014). Rechargeable lithium-sulfur batteries. Chem. Rev. doi:10.1021/cr500062v

Manthiram, A., Fu, Y., and Su, Y. S. (2013). Challenges and prospects of lithiumsulfur batteries. Acc. Chem. Res. 46, 1125-1134. doi:10.1021/ar300179v

Manuel Stephan, A. (2006). Review on gel polymer electrolytes for lithium batteries. Eur. Polym. J. 42, 21-42. doi:10.1016/j.eurpolymj.2005.09.017

Marmorstein, D., Yu, T. H., Striebel, K. A., McLarnon, F. R., Hou, J., and Cairns, E. J. (2000). Electrochemical performance of lithium/sulfur cells with three different polymer electrolytes. J. Power Sources 89, 219-226. doi:10.1016/S0378-7753(00) 00432-8

Mikhaylik, Y., Kovalev, I., Schock, R., Kumaresan, K., Xu, J., and Affinito, J. (2010). High energy rechargeable Li-S cells for EV application. status, remaining problems and solutions. ECS Trans. 25, 23-34. doi:10.1149/1.3414001

Nagao, M., Hayashi, A., and Tatsumisago, M. (2011). Sulfur-carbon composite electrode for all-solid-state Li/S battery with Li2S-P2S5 solid electrolyte. Electrochim Acta 56, 6055-6059. doi:10.1016/j.electacta.2011.04.084 
Nagao, M., Hayashi, A., and Tatsumisago, M. (2012). Fabrication of favorable interface between sulfide solid electrolyte and Li metal electrode for bulk-type solid-state Li/S battery. Electrochem. Commun. 22, 177-180. doi:10.1016/j. elecom.2012.06.015

Nagao, M., Imade, Y., Narisawa, H., Kobayashi, T., Watanabe, R., Yokoi, T., et al. (2013). All-solid-state Li-sulfur batteries with mesoporous electrode and thio-LISICON solid electrolyte. J. Power Sources 222, 237-242. doi:10.1016/j. jpowsour.2012.08.041

Nagata, H., and Chikusa, Y. (2014). A lithium sulfur battery with high power density. J. Power Sources 264, 206-210. doi:10.1016/j.jpowsour.2014.04.106

Park, J.-W., Yamauchi, K., Takashima, E., Tachikawa, N., Ueno, K., Dokko, K., et al. (2013a). Solvent effect of room temperature ionic liquids on electrochemical reactions in lithium-sulfur batteries. J. Phys. Chem. C 117, 4431-4440. doi:10.1021/jp400153m

Park, J. W., Ueno, K., Tachikawa, N., Dokko, K., and Watanabe, M. (2013b). Ionic liquid electrolytes for lithium-sulfur batteries. J. Phys. Chem. C 117, 20531-20541. doi:10.1021/Jp408037e

Przyluski, J., Siekierski, M., and Wieczorek, W. (1995). Effective-medium theory in studies of conductivity of composite polymeric electrolytes. Electrochim. Acta 40, 2101-2108. doi:10.1016/0013-4686(95)00147-7

Robertson, A. D., West, A. R., and Ritchie, A. G. (1997). Review of crystalline lithiumion conductors suitable for high temperature battery applications. Solid State Ionics 104, 1-11. doi:10.1016/S0167-2738(97)00429-3

Ryu, H.-S., Ahn, H.-J., Kim, K.-W., Ahn, J.-H., and Lee, J.-Y. (2006). Discharge process of Li/PVdF/S cells at room temperature. J. Power Sources 153, 360-364. doi:10.1016/j.jpowsour.2005.05.037

Scheers, J., Fantini, S., and Johansson, P. (2014). A review of electrolytes for lithiumsulphur batteries. J. Power Sources 255, 204-218. doi:10.1016/j.jpowsour.2014. 01.023

Scrosati, B. (1972). Recent advances in lithium solid state batteries. J. Appl. Electrochem. 2, 7. doi:10.1007/BF02354981

Shim, J., Striebel, K. A., and Cairns, E. J. (2002). The lithium/sulfur rechargeable cell. J. Electrochem. Soc. 149, A1321. doi:10.1149/1.1503076

Shin, J. H., and Cairns, E. J. (2008a). Characterization of N-methyl-Nbutylpyrrolidinium Bis(trifluoromethanesulfonyl)imide-LiTFSI-Tetra(ethylene glycol) dimethyl ether mixtures as a Li metal cell electrolyte. J. Electrochem. Soc. 155, A368-A373. doi:10.1149/1.2869876

Shin, J. H., and Cairns, E. J. (2008b). N-Methyl-(n-butyl)pyrrolidinium bis(trifluoromethanesulfonyl)imide-LiTFSI-poly(ethylene glycol) dimethyl ether mixture as a Li/S cell electrolyte. J. Power Sources 177, 537-545. doi:10.1016/j.jpowsour.2007.11.043

Shin, J. H., Jung, S. S., Kim, K. W., Ahn, H. J., and Ahn, J. H. (2002a). Preparation and characterization of plasticized polymer electrolytes based on the PVdF-HFP copolymer for lithium/sulfur battery. J. Mater. Sci. Mater. Electron. 13, 727-733. doi:10.1023/A:1021521207247

Shin, J. H., Kim, K. W., Ahn, H. J., and Ahn, J. H. (2002b). Electrochemical properties and interfacial stability of (PEO)(10)LiCF3SO3-TinO2n-1 composite polymer electrolytes for lithium/sulfur battery. Mater. Sci. Eng. B Solid State Mater. Adv. Technol. 95, 148-156. doi:10.1016/S0921-5107(02)00226-X

Song, J. Y., Wang, Y. Y., and Wan, C. C. (1999). Review of gel-type polymer electrolytes for lithium-ion batteries. J. Power Sources 77, 183-197. doi:10.1016/ S0378-7753(98)00193-1

Song, M. K., Cairns, E. J., and Zhang, Y. (2013). Lithium/sulfur batteries with high specific energy: old challenges and new opportunities. Nanoscale 5, 2186-2204. doi:10.1039/c2nr33044j

Stramare, S., Thangadurai, V., and Weppner, W. (2003). Lithium lanthanum titanates: a review. Chem. Mater. 15, 3974-3990. doi:10.1021/Cm0300516

Tachikawa, N., Yamauchi, K., Takashima, E., Park, J. W., Dokko, K., and Watanabe, M. (2011). Reversibility of electrochemical reactions of sulfur supported on inverse opal carbon in glyme-Li salt molten complex electrolytes. Chem. Commun. (Camb.) 47, 8157-8159. doi:10.1039/clcc12415c

Tarascon, J. M., and Armand, M. (2001). Issues and challenges facing rechargeable lithium batteries. Nature 414, 359-367. doi:10.1038/35104644

Tarascon, J. M., and Guyomard, D. (1994). New electrolyte compositions stable over the $\mathrm{O}-\mathrm{V}$ to $5-\mathrm{V}$ voltage range and compatible with the Li1+Xmn2o4 carbon Li-ion cells. Solid State Ionics 69, 293-305. doi:10.1016/0167-2738(94) 90418-9
Teragawa, S., Aso, K., Tadanaga, K., Hayashi, A., and Tatsumisago, M. (2014). Preparation of Li2S-P2S5 solid electrolyte from N-methylformamide solution and application for all-solid-state lithium battery. J. Power Sources 248, 939-942. doi:10.1016/j.jpowsour.2013.09.117

Thangadurai, V., Narayanan, S., and Pinzaru, D. (2014). Garnet-type solid-state fast Li ion conductors for Li batteries: critical review. Chem. Soc. Rev. 43, 4714-4727. doi: $10.1039 / \mathrm{c} 4 \mathrm{cs} 00020 \mathrm{j}$

Thangadurai, V., and Weppner, W. (2006). Recent progress in solid oxide and lithium ion conducting electrolytes research. Ionics 12, 81-92. doi:10.1007/s11581-0060013-7

Tobishima, S. I., Yamamoto, H., and Matsuda, M. (1997). Study on the reduction species of sulfur by alkali metals in nonaqueous solvents. Electrochim. Acta 42, 1019-1029. doi:10.1016/S0013-4686(96)00281-2

Wang, D. W., Zhou, G., Li, F., Wu, K. H., Lu, G. Q., Cheng, H. M., et al. (2012). A microporous-mesoporous carbon with graphitic structure for a high-rate stable sulfur cathode in carbonate solvent-based Li-S batteries. Phys. Chem. Chem. Phys. 14, 8703-8710. doi:10.1039/c2cp40808b

Wang, J., Chew, S. Y., Zhao, Z. W., Ashraf, S., Wexler, D., Chen, J., et al. (2008). Sulfur-mesoporous carbon composites in conjunction with a novel ionic liquid electrolyte for lithium rechargeable batteries. Carbon N. Y. 46, 229-235. doi:10.1016/j.carbon.2007.11.007

Wang, J. L., Yang, J., Wan, C. R., Du, K., Xie, J. Y., and Xu, N. X. (2003). Sulfur composite cathode materials for rechargeable lithium batteries. Adv. Funct. Mater. 13, 487-492. doi:10.1002/adfm.200304284

Wang, J. L., Yang, J., Xie, J. Y., Xu, N. X., and Li, Y. (2002). Sulfur-carbon nanocomposite as cathode for rechargeable lithium battery based on gel electrolyte. Electrochem. Commun. 4, 499-502. doi:10.1149/1.1461377

Wang, L. N., and Byon, H. R. (2013). N-Methyl-N-propylpiperidinium bis(trifluoromethanesulfonyl)imide-based organic electrolyte for high performance lithium-sulfur batteries. J. Power Sources 236, 207-214. doi:10.1016/j. jpowsour.2013.02.068

Wang, W. K., Wang, Y., Huang, Y. Q., Huang, C. J., Yu, Z. B., Zhang, H., et al. (2010). The electrochemical performance of lithium-sulfur batteries with $\mathrm{LiClO} 4$ DOL/DME electrolyte. J. Appl. Electrochem. 40, 321-325. doi:10.1007/s10800009-9978-z

Weston, J. E., and Steele, B. C. H. (1982). Effects of inert fillers on the mechanical and electrochemical properties of lithium salt poly (ethylene-oxide) polymer electrolytes. Solid State Ionics 7, 75-79. doi:10.1016/0167-2738(82)90072-8

Xin, S., Gu, L., Zhao, N. H., Yin, Y. X., Zhou, L. J., Guo, Y. G., et al. (2012). Smaller sulfur molecules promise better lithium-sulfur batteries. J. Am. Chem. Soc. 134, 18510-18513. doi:10.1021/ja308170k

Xiong, S. Z., Xie, K., Diao, Y., and Hong, X. B. (2013). On the role of polysulfides for a stable solid electrolyte interphase on the lithium anode cycled in lithium-sulfur batteries. J. Power Sources 236, 181-187. doi:10.1016/j.jpowsour. 2013.02.072

Xu, G. Y., Ding, B., Pan, J., Nie, P., Shen, L. F., and Zhang, X. G. (2014). High performance lithium-sulfur batteries: advances and challenges. J. Mater. Chem. A 2, 12662-12676. doi:10.1039/C4ta02097a

$\mathrm{Xu}$, J. J., and Ye, H. (2005). Polymer gel electrolytes based on oligomeric polyether/cross-linked PMMA blends prepared via in situ polymerization. Electrochem. Commun. 7, 829-835. doi:10.1016/j.elecom.2005.04.034

$\mathrm{Xu}$, K. (2004). Nonaqueous liquid electrolytes for lithium-based rechargeable batteries. Chem. Rev. 104, 4303-4417. doi:10.1021/Cr030203g

$\mathrm{Xu}, \mathrm{K}$., and Angell, C. A. (2002). Sulfone-based electrolytes for lithium-ion batteries. J. Electrochem. Soc. 149, A920-A926. doi:10.1149/1.1483866

Yamaki, J. I., Tobishima, S. I., Sakurai, Y., Saito, K. I., and Hayashi, K. (1998). Safety evaluation of rechargeable cells with lithium metal anodes and amorphous V2O5 cathodes. J. Appl. Electrochem. 28, 135-140. doi:10.1023/A: 1003270406759

Yamin, H., and Peled, E. (1983). Electrochemistry of a non-aqueous lithium sulfur cell. J. Power Sources 9, 281-287. doi:10.1016/0378-7753(83)87029-3

Yan, Y., Yin, Y. X., Xin, S., Su, J., Guo, Y. G., and Wan, L. J. (2013). High-safety lithium-sulfur battery with prelithiated $\mathrm{Si} / \mathrm{C}$ anode and ionic liquid electrolyte. Electrochim. Acta 91, 58-61. doi:10.1016/j.electacta.2012.12.077

Yang, Y., Zheng, G., and Cui, Y. (2013). A membrane-free lithium/polysulfide semi-liquid battery for large-scale energy storage. Energy Environ. Sci. 6, 1552. doi: $10.1039 / \mathrm{c} 3$ ee $00072 \mathrm{a}$ 
Yim, T., Park, M.-S., Yu, J.-S., Kim, K. J., Im, K. Y., Kim, J.-H., et al. (2013). Effect of chemical reactivity of polysulfide toward carbonate-based electrolyte on the electrochemical performance of Li-S batteries. Electrochim. Acta 107, 454-460. doi:10.1016/j.electacta.2013.06.039

Yin, Y. X., Xin, S., Guo, Y. G., and Wan, L. J. (2013). Lithium-sulfur batteries: electrochemistry, materials, and prospects. Angew. Chem. Int. Ed. Engl. 52, 13186-13200. doi:10.1002/anie.201304762

Yuan, L. X., Feng, J. K., Ai, X. P., Cao, Y. L., Chen, S. L., and Yang, H. X. (2006). Improved dischargeability and reversibility of sulfur cathode in a novel ionic liquid electrolyte. Electrochem. Commun. 8, 610-614. doi:10.1016/j.elecom.2006. 02.007

Zhang, B., Qin, X., Li, G. R., and Gao, X. P. (2010). Enhancement of long stability of sulfur cathode by encapsulating sulfur into micropores of carbon spheres. Energy Environ. Sci. 3, 1531. doi:10.1039/c002639e

Zhang, S. S. (2012). Role of LiNO3 in rechargeable lithium/sulfur battery. Electrochim. Acta 70, 344-348. doi:10.1016/j.electacta.2012.03.081

Zhang, S. S. (2013). Liquid electrolyte lithium/sulfur battery: fundamental chemistry, problems, and solutions. J. Power Sources 231, 153-162. doi:10.1016/j. jpowsour.2012.12.102

Zhang, S. S., and Read, J. A. (2012). A new direction for the performance improvement of rechargeable lithium/sulfur batteries. J. Power Sources 200, 77-82. doi:10.1016/j.jpowsour.2011.10.076

Zhang, S. S., and Tran, D. T. (2012). A proof-of-concept lithium/sulfur liquid battery with exceptionally high capacity density. J. Power Sources 211, 169-172. doi:10.1016/j.jpowsour.2012.04.006

Zhang, S. S., and Tran, D. T. (2013). How a gel polymer electrolyte affects performance of lithium/sulfur batteries. Electrochim. Acta 114, 296-302. doi:10.1016/ j.electacta.2013.10.069
Zhao, Y., Zhang, Y., Gosselink, D., Doan, T. N., Sadhu, M., Cheang, H. J., et al. (2012). Polymer electrolytes for lithium/sulfur batteries. Membranes (Basel) 2, 553-564. doi:10.3390/membranes2030553

Zheng, S., Han, P., Han, Z., Zhang, H., Tang, Z., and Yang, J. (2014). High performance C/S composite cathodes with conventional carbonate-based electrolytes in Li-S battery. Sci. Rep. 4, 4842. doi:10.1038/srep04842

Zhu, X. J., Wen, Z. Y., Gu, Z. H., and Lin, Z. X. (2005). Electrochemical characterization and performance improvement of lithium/sulfur polymer batteries. J. Power Sources 139, 269-273. doi:10.1016/j.jpowsour.2004.07.002

Conflict of Interest Statement: The authors declare that the research was conducted in the absence of any commercial or financial relationships that could be construed as a potential conflict of interest.

Received: 13 November 2014; accepted: 22 January 2015; published online: 11 February 2015.

Citation: $\mathrm{Li}$ G, Li Z, Zhang B and Lin $Z$ (2015) Developments of electrolyte systems for lithium-sulfur batteries: a review. Front. Energy Res. 3:5. doi: 10.3389/fenrg.2015.00005

This article was submitted to Energy Storage, a section of the journal Frontiers in Energy Research.

Copyright (c) $2015 \mathrm{Li}, \mathrm{Li}$, Zhang and Lin. This is an open-access article distributed under the terms of the Creative Commons Attribution License (CC BY). The use, distribution or reproduction in other forums is permitted, provided the original author(s) or licensor are credited and that the original publication in this journal is cited, in accordance with accepted academic practice. No use, distribution or reproduction is permitted which does not comply with these terms. 